\title{
Correction to: Bioaccumulation process and health risk assessment of toxic elements in tomato fruit grown under $\mathrm{Zn}$ nutrition treatment
}

\author{
Stefan M. Kolašinac • Predrag Bosnić • \\ Slavoljub S. Lekić • Jelena Golijan • Tanja Petrović • \\ Goran Todorovic • Aleksandar Ž. Kostić
}

Published online: 22 October 2018

(C) Springer Nature Switzerland AG 2018

\section{Correction to: Environ Monit Assess (September 2018) 190:508 https://doi.org/10.1007/s10661-018-6886-x}

The original version of this article unfortunately contained a mistake in the author group, affiliation and funding information sections as well as the omitted acknowledgment section.

The corrected author group and affiliation are shown in this version. The corrected funding information and omitted acknowledgment section are presented below.

The online version of the original article can be found at https://doi.org/10.1007/s10661-018-6886-x

S. M. Kolašinac · S. S. Lekić · J. Golijan

Faculty of Agriculture, Chair of Genetics, Plant Breeding and Seed Production, University of Belgrade, Nemanjina 6,

Belgrade 11080, Serbia

\section{P. Bosnić}

Institute for Multidisciplinary Research, Department of Plant Nutrition, University of Belgrade, PO Box 33, Belgrade 11030, Serbia
Acknowledgements The authors thank Dr. Ljiljana Kostić (Laboratory of Plant Nutrition, University of Belgrade's Institute for Multidisciplinary Research) for chemical analyses of the plant and soil samples.

Funding information We are grateful to the Serbian Ministry of Education, Science and Technological Development for providing Grants OI 173028 (to Miroslav Nikolić) and TR 31003 for this study.

T. Petrović $\cdot$ G. Todorovic

Maize Research Institute "Zemun Polje”, Slobodana Bajica 1, Belgrade 11185, Serbia

\section{A. Ž. Kostić $(\bowtie)$}

Faculty of Agriculture, Chair of Chemistry and Biochemistry, University of Belgrade, Nemanjina 6, Belgrade 11080, Serbia e-mail: akostic@agrif.bg.ac.rs 